\title{
Renewable energy from the waste soles through thermal pyrolysis-A novel approach
}

\author{
M. A. Hashem ${ }^{1 *}$, A. C. Paul, S. Hosen and A. Hasan \\ Department of Leather Engineering, Khulna Univerity of Engineering \& Technology (KUET), Khulna-9203, Bangladesh
}

\begin{abstract}
Footwear is a booming sector in Bangladesh. Disposing of process residues from the footwear industries, especially production waste of thermoplastic rubber and polyvinyl chloride soles as well as human used soles is a big concern due to its non-biodegradability. In this work, waste thermoplastic rubber (TPR) and polyvinylchloride (PVC) soles were used as an energy source through the fixed-bed-fire-tube heating pyrolysis to reduce the pollution load. The experiments were performed at varying temperature within the range of $250^{\circ} \mathrm{C}$ to $450^{\circ} \mathrm{C}$ at every $100^{\circ} \mathrm{C}$ interval for each case. In pyrolysis oil, char and gas were produced from the both TPR and PVC soles; temperature increment was created more percentage of oil from the both soles. At same condition TPR sole was produced $12.3 \%$ more oil than PVC sole. The pyrolytic oils were made fractional distillation; obtained liquids were relatively greater in volume and low boiling range. The obtained liquids from the fractional distillation were exhibited more light fractions present in the pyrolytic polyvinyl chloride oil (PPVCO) than pyrolytic thermoplastic rubber oil (PTPRO). The process could be optimized for the large scale, which will offer advantages to reduce the environmental impact as well as the production of new product from the waste soles.
\end{abstract}

Keywords: Thermoplastic rubber; Polyvinyl chloride; Pyrolysis; Oil; Char; Fractional distillation

\section{Introduction}

Bangladesh is one of the developing and most densely populated countries with a total population of 166 million. The demand for energy is growing due to increasing the industrialization of the society concomitantly increasing the growth of population (Isler et al., 2010). Growing population lead to the rapid industrialization subsequently disposal of wastes is also significantly increasing day by day.

Footwear is one of the most important sectors in Bangladesh. Footwear is the wearing apparel for the foot with basic two parts: i) upper and ii) bottom (sole). In most cases, the upper part is leather, synthetic, or canvas. On the other hand, the bottom (sole) is composed of thermoplastic rubber (TPR), polyvinyl chloride (PVC), ethyl vinyl acetate (EVA), vulcanized rubber (VR), leather, etc. In Bangladesh, most of the footwear industries are using polyvinyl chloride (PVC) and thermoplastic rubber (TPR) as sole for the production of footwear.

Whatever the soles (TPR, PVC, EVA, VR, leather, etc.) are used for the production of footwear after a certain period users indiscriminately discard it as waste. Disposal of organic wastes e.g. sole, tire, etc. from the anthropogenic activity is a growing environmental issue for the modern society, especially in the developing country due to its non-biodegradability. In the recent year, footwear industries in Bangladesh are increasing day by day and disposal of waste organic soles (PVC, TPR, etc.) are also increased. Open air dumping of tires, soles may act as the best breeding grounds for disease-carrying mosquitoes with the aid of rain water (Islam et al., 2011). It is reported that vinyl is the major source of dioxin (Thornton, 2002). Landfill is the most common way of disposing waste soles. But the disposal of land filling is not viable due to its non-biodegradability. During life span, PVC forms organochlorines and emits hazardous substances, which is harmful to the environment (Schwarzenegger and Adams, 2006).

To survive the industrial sector waste generation, disposal and minimization has become a great challenge. Cleaner production is the prime need for the forthcoming generation for the good environment. Increasing population alongside raising environmental awareness means that waste treatment and disposal practices of past are no longer acceptable. It is

\footnotetext{
* Corresponding author e-mail: hashem_518@yahoo.com, mahashem@le.kuet.ac.bd
} 
reported that every year waste generation per capita is increasing (Tabasová et al., 2012); simultaneously energy consumption is also increased with the limited fossil fuel.

Now-a-days energy crisis is increasing. Renewable energy should be widely investigated in order to renovate energy sources to keep sustainable development. Conversion of waste-to-energy (WTE) is an important strategy for waste treatment. The method could lead to sanitize the disposal of waste. Pyrolysis is an attractive method of recycling the organic waste, i.e. recycling of tires (Islam et al., 2011). Since the soling materials of PVC and TPR are non-biodegradable as they could not easily return to the natural carbon cycle, hence life cycle of soling materials end at the waste disposal facilities (Luo et al., 2000).

In the pyrolysis, thermo-chemical process involves the heating of organic waste material at a higher temperature in the absence of oxygen to break them down to simpler organic compounds. Carbon, solid char, oil and gas are produced by the pyrolysis of organic solid wastes (Lloyd, 2006). The solid char is a carbonaceous material which is used for the production of activated carbon (Gonzalez et al., 2009; Barbooti et al., 2004).

In the last few decades, various pyrolysis processes have been carried out for the rickshaw/ bicycle tires (Li et al., 2004; Islam et al., 2010; Kaminsky, 1995). Among the pyrolysis processes, Islam et al., (2007) has been successfully studied the fixed-bed-fire-tube heating pyrolysis process for the rickshaw/bicycle tires. So far, no report has been published for the pyrolysis of the waste soles, especially TPR or PVC soles. The TPR compounds are articulated by styrene-butadiene-styrene (SBS) or styrene- ethylene/butadiene-styrene (SEBS) block copolymers. The chemical composition of SBS and PVC is shown in the Fig. 1.

In this work, waste thermoplastic rubber and polyvinyl chloride soles were used as an energy source through the fixed-bed-fire-tube heating pyrolysis to reduce the pollution load. The benefit of thermal treatment is to reduce the volume of waste soles over common land filling.

\section{Materials and methods}

\section{Sampling}

The waste TPR and PVC soles were collected from the different sources including a footwear industry, Amar Ekushey Hall, Khulna University of Engineering \& Technology as well as a nearby local area of Khulna city, Bangladesh.

\section{Sample preparation}

The soles were detached from the upper parts of footwear, washed with water to remove dirt, mud, sand and finally the soles were dried in the sun. Then, the sun-dried soles were chopped with a knife into small pieces facilitating to put into the reactor.

\section{Experimental set-up}

The experimental set-up is shown in Fig. 2. Batch wise fixed-bed-fire-tube pyrolysis heating was selected for the experiment. The reactor was made of mild steel (MS) sheet having a dimension of $40.0 \mathrm{~cm} \mathrm{~L} . \times 16.0 \mathrm{~cm} \mathrm{o.} \mathrm{d.} \times$ $14.25 \mathrm{~cm} \mathrm{i.} \mathrm{d.).} \mathrm{One} \mathrm{side} \mathrm{of} \mathrm{the} \mathrm{reactor} \mathrm{was} \mathrm{closed} \mathrm{and}$ another side was connected to the flanges which were connected to the electric heater properly sealed by the high-temperature resistance gasket.

Table I. Experimental conditions and data obtained for the TPR sole

\begin{tabular}{ccccccc}
\hline \multirow{2}{*}{ No. } & TPR sole & Temp. & \multicolumn{3}{c}{ Products $(\mathrm{kg})$} & \multicolumn{2}{c}{$\begin{array}{c}\text { Residence } \\
\text { time (min) }\end{array}$} \\
\cline { 4 - 6 } & wt. $(\mathrm{kg})$ & $\left({ }^{\circ} \mathrm{C}\right)$ & Oil & Char & Gas & 50 \\
01 & 1.3 & 250 & 0.10 & 1.14 & 0.06 & 40 \\
03 & 1.3 & 350 & 0.25 & 0.90 & 0.15 & 28 \\
\hline
\end{tabular}

Table II. Experimental conditions and data obtained for the PVC sole

\begin{tabular}{ccccccc}
\hline \multirow{2}{*}{ No. } & PVC sole & Temp. & \multicolumn{3}{c}{ Products $(\mathrm{kg})$} & \multicolumn{2}{c}{$\begin{array}{c}\text { Residence } \\
\text { time (min) }\end{array}$} \\
\cline { 4 - 6 } & wt. $(\mathrm{kg})$ & 250 & Oil & Char & Gas & 45 \\
01 & 1.3 & 350 & 0.07 & 1.18 & 0.05 & 33 \\
03 & 1.3 & 450 & 0.12 & 0.95 & 0.23 & 27 \\
\hline
\end{tabular}




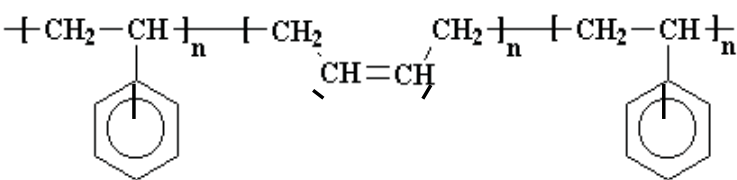

Styrene-butadine-styrene (SBS)

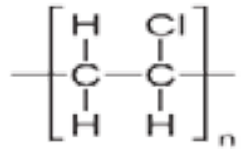

Poly vinyl chloride (PVC)

Fig. 1. Chemical compositions of the SBS and PVC

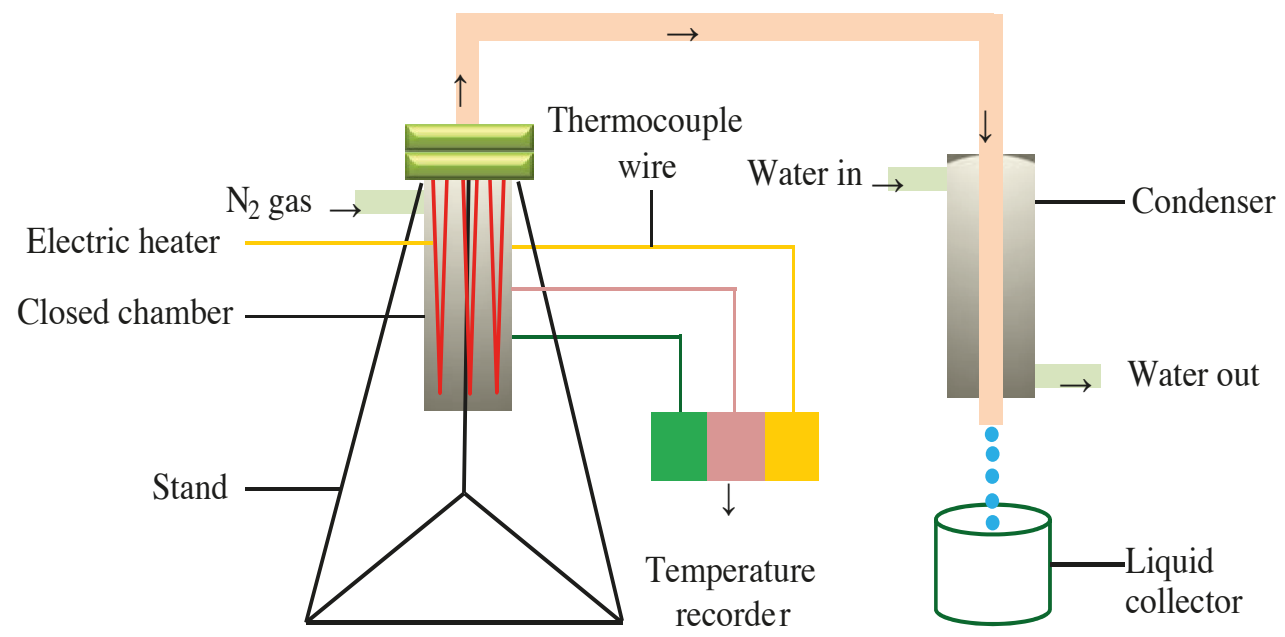

Fig. 2. Experimental set-up for the thermal pyrolysis
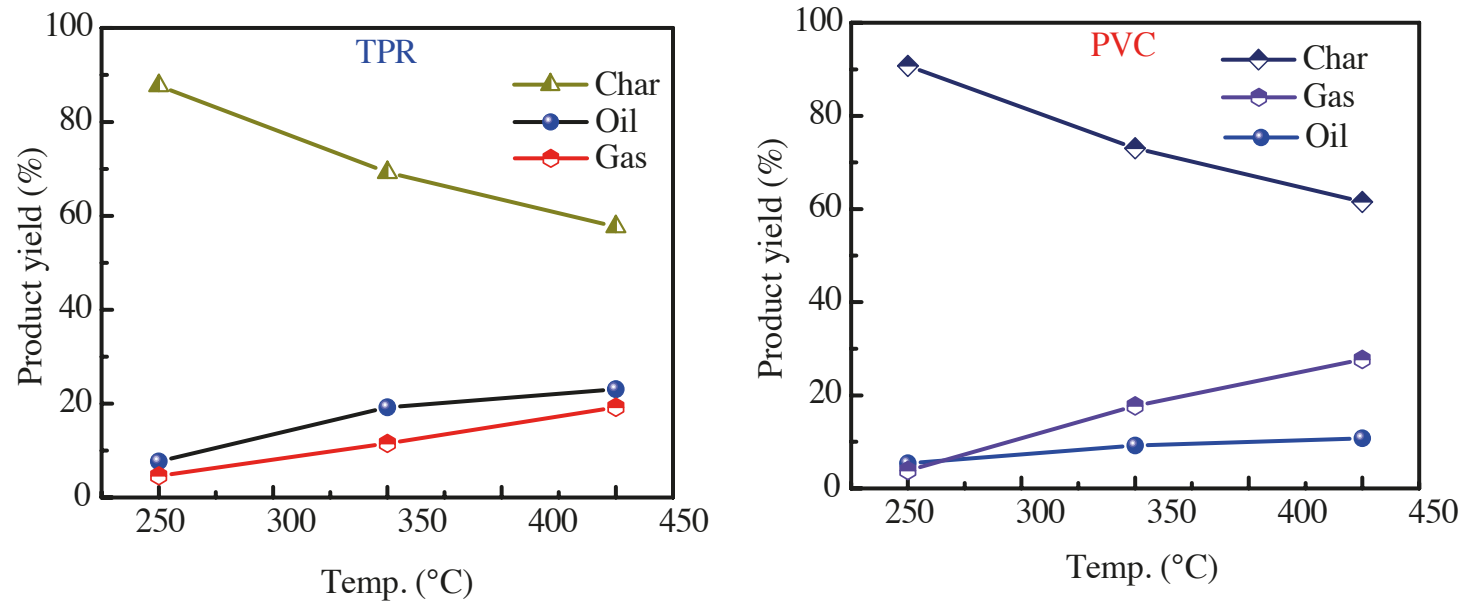

Fig. 3. Effect of temperature in the pyrolysis process 


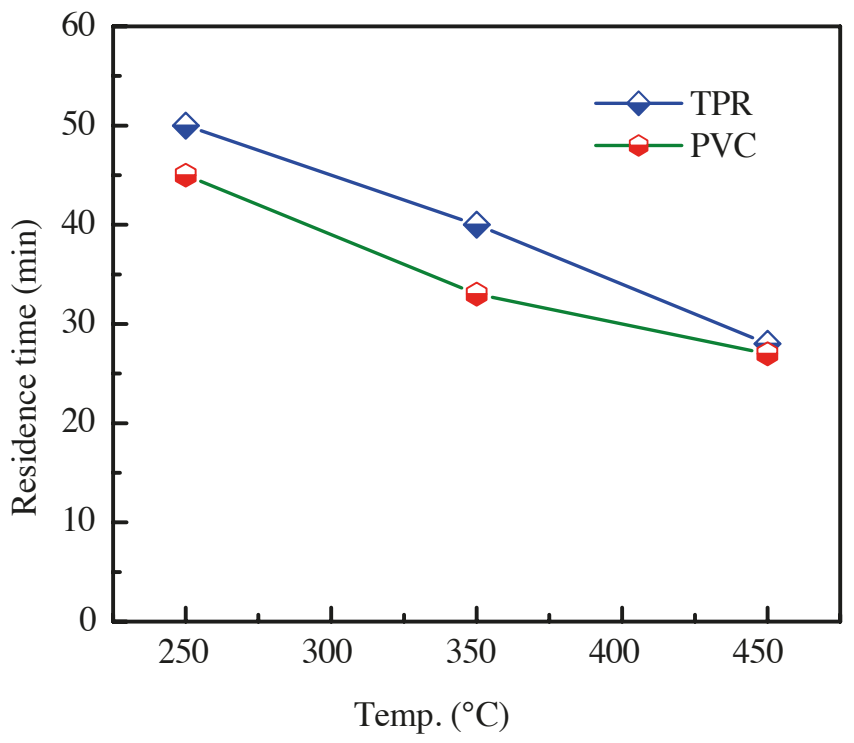

Fig. 4. Effect of residence time and thermal temperature
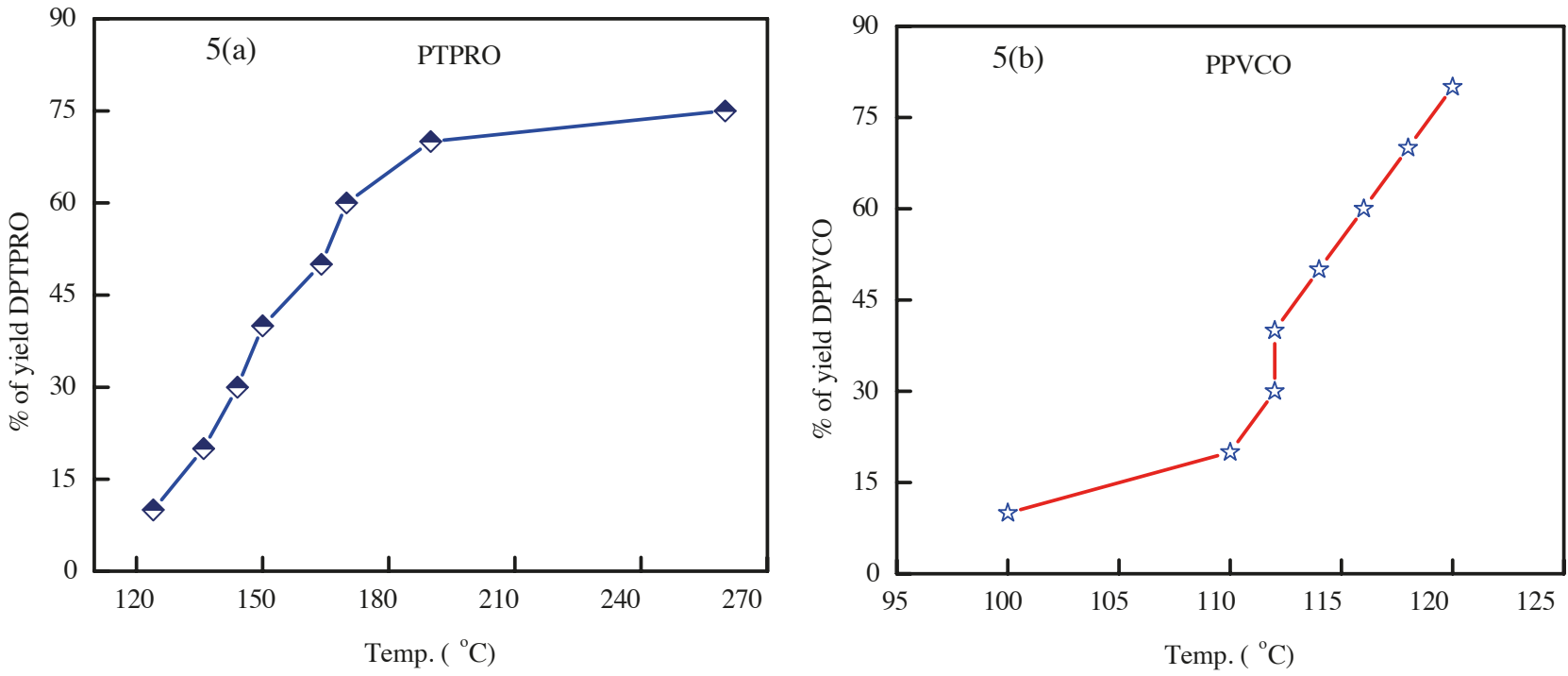

Fig. 5. Fractional distillation of the PTPRO a) and b) PPVCO

The closed chamber and pipeline were insulated to prevent the loss of heat. A copper pipe having an inner diameter of $0.5 \mathrm{~mm}$ was used as a condenser which was wrapped with the foam board to aid the condensation process of the vapor. Nitrogen $\left(\mathrm{N}_{2}\right)$ gas was supplied from a cylinder to make the chamber anaerobic condition. A pressure regulator and a gas flow meter were used to control the required gas flow rate in the chamber. A thermocouple wire was used in the system which one end was inserted into the chamber and the other end was connected to the temperature recorder to record the temperature.

\section{Determination of flash point}

Flash point is used to characterize the fire hazards of a fuel. It is the lowest temperature at which it can vaporize to form an ignitable mixture in the air. The flash point of pyrolytic thermoplastic rubber oil (PTPRO) and pyrolytic polyvinyl chloride oil (PPVCO)was measured according to ASTM D 93-62 method. 


\section{Fractional distillation of the PTPRO and PPVCO}

Fractional distillation process was carried out to separate the lighter and heavier fraction of hydrocarbon present in the pyrolytic oil. The process has liquid outlets at intervals up the column which allow for the withdrawal of different fractions or products having different boiling points. The lightest products (lowest boiling point) exit from the top of the column and the heaviest products (highest boiling point) exit from the bottom of the column. By increasing the temperature of the product inside the columns, the different hydrocarbons are separated. The PTPRO and PPVCO samples were taken in the vacuum distillation process. The samples were externally heated in a closed chamber. The vapour leaving from the chamber was condensing in a water condenser and the distilled pyrolytic thermoplastic rubber oil (DPTPRO) and distilled pyrolytic polyvinyl chloride oil (DPPVCO) were collected separately. Fractional distillation of the PTPRO was done at the temperature ranges from the initial boiling point $\left(40^{\circ} \mathrm{C}\right)$ to $260^{\circ} \mathrm{C}$. In case of PPVCO, fractional distillation was done at the temperature ranges from the initial boiling point $\left(80^{\circ} \mathrm{C}\right)$ to $120^{\circ} \mathrm{C}$.

\section{Results and discussion}

\section{Yield products}

Experimental conditions for waste PVC and TPR soles e.g., sample volume, temperature and products yield are shown in Table I \& Table II. The percentage of the yield products from the TPR and PVC waste soles are shown in Fig. 3. The TPR and PVC waste soles were used in the pyrolysis. The process was carried out in the temperature range of $250^{\circ} \mathrm{C}$ to $450^{\circ} \mathrm{C}$ at aninterval of $100^{\circ} \mathrm{C}$. Three types of products were obtained: oil, char, and gas. At the same conditions, the percentages of the yield products were varied for the TPR and PVC waste soles.

\section{Temperature effect on pyrolysis}

It is clear from the Fig. 3 that temperature was significantly effective on the pyrolysis process to produce new products. With the increasing temperature in the pyrolysis, the main yield of products (oil and char) was also increased. In the pyrolysis of TPR waste sole, at $350^{\circ} \mathrm{C}$ oil and char were $19.2 \%$ and $69.2 \%$, whereas at $450^{\circ} \mathrm{C}$ oil and char were $23.1 \%$ and $57.7 \%$ respectively. In case of pyrolysis of PVC waste sole, at $350^{\circ} \mathrm{C}$ oil and char were $9.2 \%$ and $73.1 \%$, whereas at $450^{\circ} \mathrm{C}$ oil and char were $10.8 \%$ and $61.5 \%$. It observed that at $350^{\circ} \mathrm{C}$ and $450^{\circ} \mathrm{C}$ temperature, TPR produced oil twice than PVC waste sole. The probable reason is that in pyrolysis, the
TPR articulated compounds (Fig. 1) were breaking them down into simpler liquid organic compounds. On the other hand, in the pyrolysis of PVC sole, more chlorine gas was produced rather than the liquid organic compounds. It was noticed that with an increasing temperature the product in oil was increased from the both soles.

\section{Effect of residence time on pyrolysis}

The effect of residence time on the yield of products is shown in the Fig. 4. It is obvious that at low temperature, more residence time was required to complete the conversion resulting incomplete decomposition of waste soles, which produced more char and the least amount of oil. On the other hand, higher temperature with less residence time was required to complete the conversion of waste soles resulting more oil. It could be concluded that higher temperature with less residence time was suitable to convert the long polymer chain to break them down into smaller organic compounds.

\section{Flash point}

The flash point of PTPRO and PPVCO was $28^{\circ} \mathrm{C}$ and $30^{\circ} \mathrm{C}$, respectively. Lower flash point indicates the presence of highly volatile materials in the fuel, which is a serious safety concern during handling and transportation. The flash point of furnace oil $\left(66^{\circ} \mathrm{C}\right)$, diesel $\left(58.5^{\circ} \mathrm{C}\right)$, and kerosene $\left(51^{\circ} \mathrm{C}\right)$ is higher than TPR and PVC (Khan et al., 2016), which indicate that these are easy to handle. Therefore, flash point of PTPRO and PPVCO are highly flammable oil than any other conventional diesel oil and which might be similar to kerosene oil.

\section{Fractional distillation}

In Fig. 5a and 5b show the results of fractional distillation of PTPRO and PPVCO. Fig. 5a signifies that with increasing the temperature, percentage of collected DPTPRO products was also increased. At temperature $124^{\circ} \mathrm{C}$, collection was only $10 \%$ whereas at temperature $190^{\circ} \mathrm{C}$ collection was $70 \%$. Then, the percentage of collected DPTPRO products was almost constant $(75 \%)$ at temperature $260^{\circ} \mathrm{C}$ and the remaining products were solid. In Fig. 5b, fractional distillation of PPVCO, 40\% DPPVCO was obtained at temperature $112^{\circ} \mathrm{C}$; after that, collection percentage of products from the DPTPRO was very steep. The highest percentage of DPPVCO products was collected $(80 \%)$ at temperature $120^{\circ} \mathrm{C}$.

The liquids obtained in fractional distillation process were relatively greater in volume and low boiling range. The 
obtained distilled fuel-like liquids showed more light fractions were present in PPVCO than PTPRO. However, the distilled fuel-like liquid was highly volatile in nature.

\section{Conclusion}

Thermal decomposition of TPR and PVC soles under anaerobic conditions produced oil, char, and gas. With the increasing temperature from $250^{\circ} \mathrm{C}$ to $450^{\circ} \mathrm{C}$, yield of oil and gas were increased while the char was decreased. The pyrolytic oils were made fractional distillation; obtained liquids were relatively greater in volume and low boiling range. The liquids obtained in fractional distillation exhibited more light fractions present in the pyrolytic polyvinyl chloride oil than pyrolytic thermoplastic rubber oil. The distilled liquids were highly volatile in nature. The process could be optimized for large scale, which will offer advantage to reduce the environmental impact as well as the production of new product from the waste soles.

\section{References}

Barbooti MM, Mohamed TJ, Hussain AA and Abas FO (2004), Optimization of pyrolysis conditions of scrap tires under inert gas atmosphere, Journal of Analytical and Applied Pyrolysis 72: 165-170.

Gonzalez JF, Roman S, Encinar JM and Martinez G (2009), Pyrolysis of various biomass residues and char utilization for the production of activated carbons, Journal of Analytical and Applied Pyrolysis 85: 134-141.

Islam MR, Joardder MUH, Hasan SM, Takai K and Haniu H (2011), Feasibility study for the thermal treatment of solid tire wastes in Bangladesh by using pyrolysis technology, Waste Management 31:2142-2149.

Islam MR, Parveen M and Haniu H (2010), Properties of sugarcane waste-derived bio-oils obtained by fixed-bed fire-tube heating pyrolysis, Bioresource Technology 101: 4162-4168.

Islam MR, Haniu H and Beg MRA (2007), Limonene-rich liquids from pyrolysis of heavy automotive tire wastes, Journal of Environment and Engineering 2: 681-695.

Isler A, Sundu S, Tuter M and Karaosmanoglu F (2010), Transesterification reaction of the fat originated from solid waste of the leather industry, Waste Management 30: 2631-2635.
Kaminsky W (1995), Chemical Recycling of Mixed Plastics by Pyrolysis, Advances in Polymer Technology 14: 337-344.

Li S-Q, Yao Q, Chi Y, Yan J-H and Cen K-F (2004), Pilot-Scale Pyrolysis of Scrap Tires in a Continuous Rotary Kiln, Industrial \& Engineering Chemistry Research 43: 5133-5145.

Lloyd AC (2006), Technology Evaluation and Economic Analysis of Waste Tyre Pyrolysis,Gasification, and Liquefaction, Ph.D, Secretary, California Environmental Protection.

Luo G, Suto T, Yasu S and Kato K (2000), Catalytic degradation of high density polyethylene and polypropylene into liquid fuel in a powder-particle fluidized bed, Polymer Degradation and Stability 70: 97-102.

Schwarzenegger A and Adams LS (2006), Health Concerns and Environmental Issues with PVC-Containing Building Materials in Green Buildings, Integrated Waste Management Board, California, USA.

Tabasová A, Kropác J, Kermes V, Nemet A and Stehlík P (2012), Waste-to-energy technologies: Impact on environment, Energy 44: 146-155.

Thornton J (2002), Environmental Impacts of Polyvinyl Chloride Building Materials, A Healthy Building Network Report, Washington, D.C., The United States.

Khan MZH, Sultana M, Al-Mamun MR and Hasan MR (2016), Pyrolytic Waste Plastic Oil and Its Diesel Blend: Fuel Characterization. Journal of Environmental and Public Health 2016: 1-6.

Received: 17 August 2016; Revised: 19 September 2016; Accepted: 28 December 2016. 